\title{
A RETROSPECTIVE STUDY OF POISONING CASES IN MANMOHAN MEMORIAL TEACHING HOSPITAL
}

\author{
Bajracharya $\mathrm{M}^{1^{*}}$ Khadka $\mathrm{P}^{1}$, Wagle $\mathrm{L}^{1}$ \\ ${ }^{1}$ Department of Pharmacy, Manmohan Memorial Institute of Health Sciences, Soalteemode, \\ Kathmandu, Nepal \\ *Corresponding author:
}

Mijala Bajracharya, Lecturer, Department of Pharmacy, Manmohan Memorial Institute of Health, Sciences, Soalteemode, Kathmandu,Nepal, Email :bmijala@yahoo.com

\section{ABSTRACT}

Background: Poisoning is one of the leading causes of morbidity and mortality in Nepal and also a major public health problem worldwide. It needs specific epidemiological surveillance to determine the extent and pattern of poisoning of a place, and to take preventive measures. Hence this study is aimed to explore the demographic, etiological, and clinical characteristics of poisoning cases of MMTH and to assess the effect of variables such as age, sex, and agent of poisoning frequency.

Methods: A retrospective, descriptive, unicentric and semi-quantitative study was conducted in a year of 2074 at Manmohan memorial teaching hospital after institution review committee approval in customised data collection form. Data from Baishakh 2070 (April 2013) to Kartik 2074 (October 2017) were reviewed. The data was entered in SPSS 16 version for analysis.

Result: Among 144 patients, poisoning was common among people from the age group of 15-25 years and 26-40 years. The females were more vulnerable than male. The male to female ratio was 1:1.4. Married females (32\%) and married males (31\%) were more vulnerable than unmarried ones. Poisoning incidence was found more during night $(40.3 \%)$ and midnight $(18.80 \%) .81 .2 \%$ of poisoning cases were found with suicidal intention. Organophosphorous poisoning was abundant with 75 cases.

Conclusion: This study reveals that OP poisoning is most common for self-harm with females and young at more risk. Therefore, awareness among youths is a must.

Keywords: Organophosphorous poisoning, Dichlorovos, self-harm

\section{INTRODUCTION}

Poison is an agent which, when administered into the body of a living being, can elicit a toxic response producing damage and resulting in death. A therapeutic substance is considered to be a poison if sufficiently larger doses are introduced into the body ${ }^{1}$.

Nepal is an agricultural based country and hence people have an increased access to pesticides, insecticides, and rodenticides. This predisposes the population to choose organophosphorous and rodenticide compounds for poisoning ${ }^{2}$. Metacid also known as Methyl parathion is the most commonly ingested OP pesticide ${ }^{3}$.

Organophosphates and Drugs are the common agents causing the incidence. Whether intentional or accidental, it is the easy access to these substances that significantly adds to the incidence. Narcotic 


\section{Original Article}

Drug Control Act, 2038, prohibits misuse of Narcotics and Pesticide Act 2048 has similarly prohibited the misuse of pesticides ${ }^{4}$. However improper implementation of these has led to such problems.

Advanced medical treatment and awareness cannot wholly control this issue. Poisoning pattern of a country is very crucial in determining the health need of the society and planning the infrastructure and manpower requirement for dealing these cases effectively and efficiently ${ }^{5}$. It varies in different parts of the country depending on various factors such as demography, education, socio-economic status, local beliefs and customs ${ }^{6}$. Thus each region of the country needs specific epidemiological surveillance to determine the extent and pattern of the problem to take preventive measures. Hence, this hospital based study was done to describe the epidemiological profile and outcome, pattern, and the results of treatment of poisoned patients admitted to Manmohan Memorial Teaching Hospital (MMTH), Kathmandu, Nepal.

\section{MATERIALS AND METHODS}

\section{Study Area}

Manmohan Memorial Teaching Hospital (MMTH) is a 600 bedded hospital established under Nepal Health Care Co-operative Limited (NEHCO) in 2014 in the name of Former Prime Minister Late Manmohan Adhikari, located at Sawyambhu, Kathmandu, Nepal.

\section{Study Design}

A retrospective, unicentric and descriptive study was conducted to assess the data of poisoned patients admitted in MMTH.

\section{Data Source}

The patients getting treatment at MMTH are provided with a patient record in which the details of the patient along with the treatment pattern and other ancillary information are entered. The patient confidential case records were obtained from the Medical Records Department. Necessary patient details were ted from the cardex report such as: age, sex, address, marital status, time, types of poisoning, outcome and main drugs used in the management. The files of the poisoned patients was reviewed and entered in the patient profile form developed for the purpose of the study. The filled patient profile forms were used to obtain the necessary information.

\section{Inclusion and Exclusion Criteria}

Any patient who visited the MMTH with history of poison intake during the period Baishakh 2070 to Kartik was included in the study. The patients who were treated for food poisoning and poisoning due to living things such as snakebites, wasp stings etc were excluded.

\section{Ethical approval}

Research was conducted after approval from Institution review committee of Manmohan Memorial Institute of Health Science.

\section{Data Analysis}

All the data collected from the hospital was coded as per variables and data entry was done in SPSS data sheet and analyzed by the help of statistical software SPSS 16. Data were analyzed as per 


\section{Original Article}

objectives of the study. The analyzed data was expressed in percentages and frequencies. Microsoft excel, Microsoft word were used.

\section{RESULTS AND DISCUSSION}

\section{Age distribution of poisoning}

A total of 144 poisoning cases were studied. Among them it was found that poisoning was common among people from the age group of 15-25 years (39.6\%) and 26-40 years $(32.6 \%)$. Then showed a progressive fall as the age progresses with the geriatric age group showing least vulnerability to poisoning which was as shown in table 1. Study done by Saxena V et.al 5 in Uttarkhand showed poisoning was most common among people from the age group of 21-30 years. A study done in Bir Hospital by D.P. Singh et.al ${ }^{7}$ showed that more than three-fourth $(76.8 \%)$ of the female patients were from 16 to 25 years age group and Khadka SB et.al ${ }^{8}$ in their study found that most of the poisoning occurred in the age group 21-30 (38.8\%). Thus, adolescents and young adults are at more risk.

Table 1. Age wise distribution of poisoning

\begin{tabular}{lcc}
\hline Age & No. of cases & Percentage $(\%)$ \\
\hline Child (0-14)years & 2 & 1.4 \\
Young adult (15-25)years & 57 & 39.6 \\
Adult (26-40)years & 47 & 32.6 \\
Middle age (41-59)years & 30 & 20.8 \\
Old age (60 years \& above) & 8 & 5.6 \\
Total & 144 & 100.0 \\
\hline
\end{tabular}

\section{Gender distribution of poisoning}

Females were more vulnerable than male. The male to female ratio was 1:1.4 (60 males and 84 females) which was as shown in table 2. Similar finding was obtained in the study done in Bir Hospital by D.P. Singh et.al with male to female ratio of 1:1.3 (43 males and 56 female) ${ }^{7}$, study done by Khadka SB et.al in Kathmandu Medical College Teaching Hospital showed female to male ratio was $1.09: 1^{8}$, study done by Pokhrel $\mathrm{D}$ et.al showed female were more common to the incidence $(51.4 \%)^{4}$ and study done by Shakya RP et.al in Lumbini Medical College Teaching Hospital showed that F:M ratio was $2.1: 1^{9}$. Whereas on the contrary, study done by Saxena V et.al found the Male: Female ratio was 1.2:1 (56 Males and 49 Females $)^{5}$ and study done by A. Risal et.al showed that there were 75 males $(54.7 \%)$ and 62 females $(45.3 \%)^{10}$. 


\section{Original Article}

Table 2. Gender wise distribution of poisoning

\begin{tabular}{lcc}
\hline Gender & No. of cases & Percentage (\%) \\
\hline Female & 84 & 58.3 \\
Male & 60 & 41.7 \\
Total & 144 & 100.0 \\
\hline
\end{tabular}

Distribution of poisoning according to place

Maximum number of poisoned patients in MMTH were from Swyambhu (23.61\%) and Dhading (22.92\%) (Table 3).

Table 3. Distribution of poisoning according to place

\begin{tabular}{lcc}
\hline Address & No. of cases & Percentage (\%) \\
\hline Swyambhu & 34 & 23.6 \\
Dhading & 33 & 22.9 \\
Balaju & 18 & 12.5 \\
Nuwakot & 12 & 8.3 \\
Kalanki & 11 & 7.6 \\
Ramkot & 8 & 5.6 \\
Kavre & 7 & 4.9 \\
Dallu & 6 & 4.2 \\
Thankot & 5 & 3.5 \\
Thamel & 4 & 2.8 \\
Koteshwor & 144 & 2.1 \\
Kirtipur & 2 & 1.4 \\
Bagbazar & 3 & .7 \\
Total & 5 & 100.0 \\
\hline
\end{tabular}




\section{Original Article}

\section{Distribution of poisoning according to marital status}

Married females (32\%) and married males (31\%) were more vulnerable than unmarried ones which was as shown in table 4. It may be explained with the fact that they are the ones with the main responsibilities of the family and may be under constant stress and also they are more exposed to OP compounds. Study done by Saxena V et.al found that married females were more vulnerable than married males for poisoning. ${ }^{5}$

Table 4. Distribution of poisoning according to marital status

\begin{tabular}{lcc}
\hline Marital status & No. of cases & Percentage (\%) \\
\hline Married Female & 46 & 31.9 \\
Married Male & 44 & 30.6 \\
Unmarried Female & 36 & 25.0 \\
Unmarried Male & 18 & 12.5 \\
Total & 144 & 100.0 \\
\hline
\end{tabular}

Distribution of poisoning occurred at different times

Poisoning incidence was found more during night (40.30\%) and midnight (18.80\%) which was as shown in table 5.

Table 5. Distribution of poisoning occurred at different times

\begin{tabular}{lcc}
\hline Time & No. of cases & Percentage (\%) \\
\hline Early morning (6am -10 am) & 3 & 2.1 \\
Morning (10 am-12 pm) & 10 & 6.9 \\
Afternoon (12pm-5 pm) & 23 & 16.0 \\
Evening (5pm-10 pm) & 23 & 16.0 \\
Night (10 pm-12 am) & 58 & 40.3 \\
Midnight (12am-6 am) & 27 & 18.8 \\
Total & 144 & 100.0 \\
\hline
\end{tabular}




\section{Original Article}

\section{Manners of poisoning}

There was $81.2 \%$ of poisoning with suicidal intention which was as shown in table 6 . In this study $81.2 \%$ of cases were intentional poisoning for suicidal attempt. This finding can be matched with the findings of a study done by A.Risal et.al in Dhulikhel Hospital (78.1\%), Saxena V et. al in Uttarakhand (89\%), Shakya RP et.al in Lumbini Hospital (70.67\%). Similarly study done in Bir hospital by Singh DP et al $(98 \%)$, Kar SM et al $(95 \%)$ and Karki P et al in their study found intentional self-harm to be $89 \%{ }^{10,5,9,7,11,12}$. These studies showed that the causes of self-harm were because of variety of reasons: financial problem, domestic troubles, unsuccessful love, marital disharmony, chronic illness and loss of job.

Table 6. Manners of Poisoning

\begin{tabular}{lcc}
\hline Manner & No. of cases & Percentage (\%) \\
\hline Suicidal & 117 & 81.2 \\
Accidental & 19 & 13.2 \\
Unintentional & 8 & 5.6 \\
Total & 144 & 100.0 \\
\hline
\end{tabular}

\section{Different types of poisoning}

Among different types of poisoning cases, OP poisoning was abundant with 75 cases. And Dichlorvos and Parathion were mostly consumed OP poison which was as shown in Table 7 and Table 8. This study showed that organophosphorus poisoning $(52.10 \%)$ was the most common poisoning. The common OP poison used was Dichlorovos (Nuvan) and Parathion (Metacid).A study done by Singh DP et.al ${ }^{7}$ showed that the common insecticides used for poisoning were organophosphorus compounds mainly Methyl Parathion (Metacid) and Dichlorovos (Nuvan). Likewise study done by A.Risal ${ }^{10}$ et.al showed pesticides were the most common poisons $(78.1 \%)$ consumed, study by Saxena $\mathrm{V}$ et.al ${ }^{5}$ showed that maximum poisoning were because of Organophosphates $(57 \%)$ and study by Shakya RP et.al ${ }^{9}$ also showed Organophosphorus poisoning was most common.

Table 7. Different types of poisoning

\begin{tabular}{lcc}
\hline Types & No. of cases & Percentage $(\%)$ \\
\hline Organophosphorous Poisoning & 75 & 52.1 \\
Multiple Drug Poisoning & 11 & 7.6 \\
Rodenticide Poisoning & 11 & 7.6 \\
Corrosive Poisoning & 10 & 6.9 \\
\hline
\end{tabular}




\section{Original Article}

\begin{tabular}{|c|c|c|}
\hline Paracetamol Poisoning & 8 & 5.6 \\
\hline Alcohol Poisoning & 7 & 4.9 \\
\hline Benzodiazepine Poisoning & 5 & 3.5 \\
\hline Herbal(Nirmashi) Poisoning & 3 & 2.1 \\
\hline Mushroom Poisoning & 2 & 1.4 \\
\hline Acelofenac Overdose & 1 & .7 \\
\hline Cannabis Poisoning & 1 & .7 \\
\hline Fungicidal(Chlorothalonil) Poisoning & 1 & .7 \\
\hline Ofloxacin Overdose & 1 & .7 \\
\hline CTZ Toxicity & 1 & .7 \\
\hline Thyroxine Overdose & 1 & .7 \\
\hline Mefenamic Overdose & 1 & .7 \\
\hline Topiramate Poisoning & 1 & .7 \\
\hline Warfarin Poisoning & 1 & .7 \\
\hline CO Poisoning & 1 & .7 \\
\hline Amitryptilline Overdose & 1 & .7 \\
\hline Honey Poisoning & 1 & .7 \\
\hline Total & 144 & 100.0 \\
\hline
\end{tabular}

Table 8. Name of Organophosphorous compounds causing poisoning.

\begin{tabular}{lc}
\hline OP Compounds & Frequency \\
\hline Dichlorvos & 16 \\
Parathion & 14 \\
Cypermethrin & 13 \\
Chlorpyrifos+Cypermethrin & 13 \\
\hline
\end{tabular}




\section{Original Article}

Chlorpyrifos

Dimethoate

Unknown

Total
6

5

8

75

\section{Various antidotes used in poisoning}

In $32.6 \%$ of patients antidote was not used and the combination of Pralidoxime and Atropine (37.5\%) was mostly used antidote which was as shown in Table 9. Various pharmaceuticals were also used for poisoning. Paracetamol, Benzodiazepines and other combination preparations were frequently used. Study done by Singh D.P. et.al ${ }^{7}$ showed Paracetamol alone or combination preparations with antihistamines were the most common analgesics used and Benzodiazepines were the most commonly used anxiolytics.

Table 9. Various antidotes used in poisoning

\begin{tabular}{lcc}
\hline Antidotes & Frequency & Percentage $(\%)$ \\
\hline Pralidoxime \& Atropine & 54 & 37.5 \\
Not used & 47 & 32.6 \\
Atropine & 21 & 14.6 \\
Pralidoxime+Atropine+Glycopyrolate & 9 & 6.2 \\
N-Acetylcystine & 7 & 4.9 \\
Flumazenil & 2 & 1.4 \\
Pralidoxime & 2 & 1.4 \\
N-Acetylcystine+Glycopyrolate & 1 & .7 \\
Nalaxone & 1 & .7 \\
Total & 144 & 100.0 \\
\hline
\end{tabular}

\section{Outcomes of Poisoning}

Majority of patients $(86.8 \%)$, were healed after treatment which was as shown in Table 10. 


\section{Original Article}

Table 10. Outcomes of Poisoning

\begin{tabular}{lcc}
\hline Outcome & No. of cases & Percentage (\%) \\
\hline Healed & 125 & 86.8 \\
Morbid & 12 & 8.3 \\
Death & 7 & 4.9 \\
Total & 144 & 100.0 \\
\hline
\end{tabular}

The incidence of suicidal poisoning was more in female of age group 15-25 years (31) and 26-40 years (23), compared to males (Figure 1).

Figure 1. Relationship between age groups, gender and suicidal poisoning.

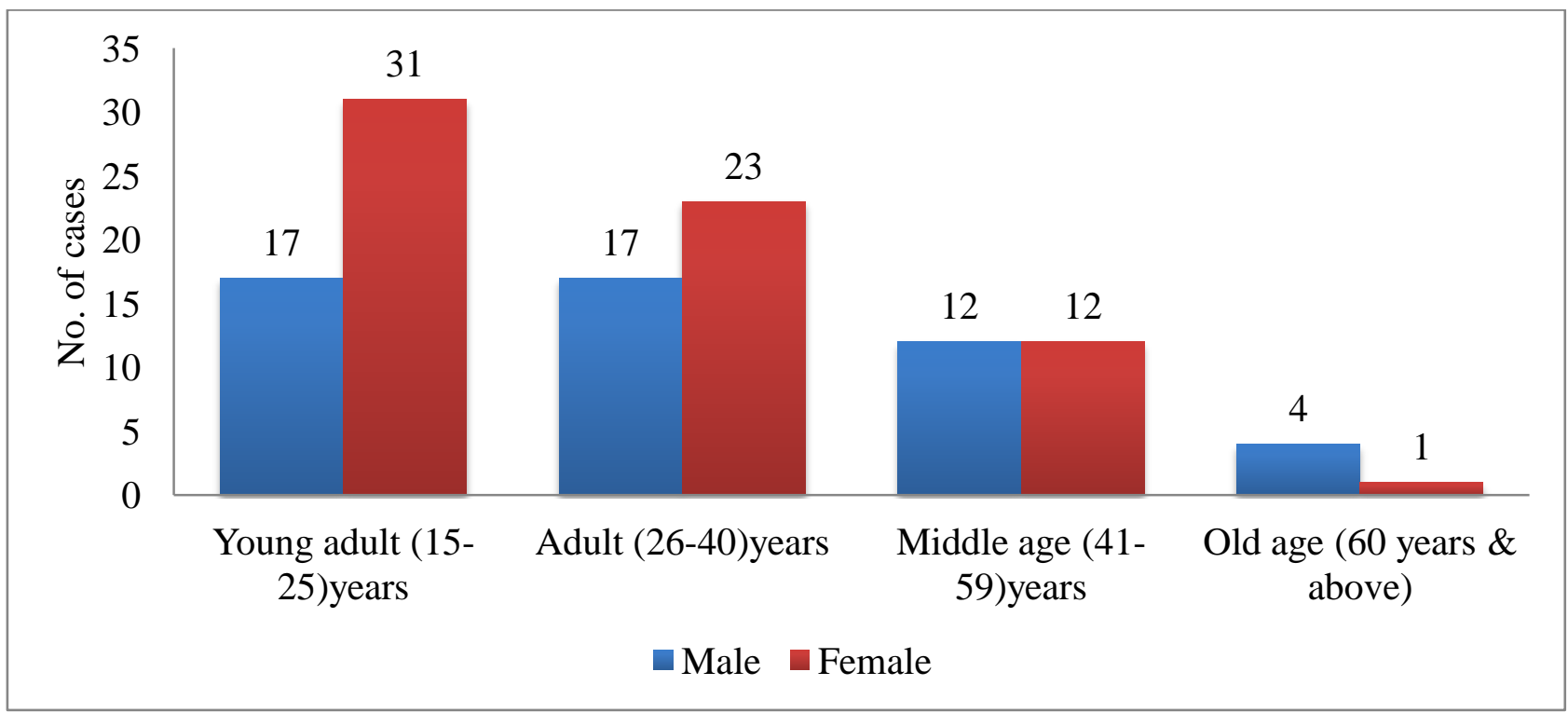

Out of 144 cases, there was total of 7 cases resulting in death of patients and among them 3 were caused by Dichlorvos, an Organophosphorous compound (Table 11). 


\section{Original Article}

Table 11. Distribution of fatal cases according to the type of poison

Fatal poison

No. of fatal cases

Dichlorvos

Aluminium Phosphide

Clonazepam+Alprazolam+Tramadol

Unknown

Total

7

\section{CONCLUSION}

This study showed females to be more vulnerable than male for poisoning. Also married persons were more vulnerable than unmarried ones. The mortality rate was found to be $5 \%$ and morbidity rate was $8 \%$. At present, pesticides remain an integral part of agricultural activities in our country and OP compounds is one of the most common poisons consumed because of its wide and easy availability. This might be the reason that OP poisoning was also very common case in MMTH. The common poison was Dichlorovos (Nuvan) and Parathion (Metacid). In this study majority of the poisoning was intentional self-harm. With the increasing stress in life, suicide among adolescents and young especially in female is a common public health problem. Thus to control this awareness programs need to be focused.

\section{CONFLICT OF INTEREST}

We declare no conflict of interest.

\section{REFERENCES}

1. Levine RR, Walsh CT, Schwartz-Bloom RD. editors. Pharmacology: Drug Actions and Reactions. 7th ed. CRC Press; 2000.

2. P. V. Kishore, S. P., R. Paudel, D. Mishra, P. Ojha, K. Alam, P. Mishra.Pattern of poisoning cases in a teaching hospital in Western Nepal. Journal of Institute of Medicine. 2008; 30(1): 2634.

3. Chataut JR, Sinha NP, Marahatta SB (2011).Pattern of Organophosphorous Poisoning: A Retrospective Community Based Study.Kathmandu university medical journal. 2011;9(34): 3134.

4. Pokhrel D, Pant S, Pradhan A, Mansoor S, A Comparative Retrospective Study of Poisoning Cases in Central, Zonal and District Hospitals. Kathmandu University Journal Of Science, Engineering and Technology. 2008. 1(5): 40-48.

5. Saxena, V., Retrospective Analysis of Pattern of Poisoning in Uttarakhand. J Indian Acad Forensic Med. 2014,36(3). 


\section{Original Article}

6. Yadav, S., Pattern of acute poisoning in children in a tertiary care hospital in eastern Nepal. International Journal of Contemporary Pediatrics. 2016; 3(3):1001-1005.

7. Singh DP, Aacharya RP. Pattern of poisoning cases in Bir Hospital. J Inst Med. 2006; 28:1: 3-6.

8. Khadka SB, Ale SB. A study of poisoning cases in emergency Kathmandu Medical College Teaching Hospital. Kathmandu Univ Med J. 2005; 3: 388-391.

9. Shakya RP, Adhikari S, Bajracharya R. Pattern of acute poisoning attending a tertiary care hospital of western Nepal. Journal of Lumbini Medical College. 2016;4(2):90-93.

10. Karki RK, Risal A. Study of Poisoning Cases in a Tertiary Care Hospital. Kathmandu Univ Med J. 2012;10(4):70- 73.

11. Kar SM, Timsinha S, Agrawal P. An Epidemiological study of Organophosphorus Poisoning at Manipal Teaching Hospital, Pokhara, Nepal. J Indian Acad Forensic Med. 32(2): 108-9.

12. Karki P, Ansari JA, Bhandary S, Koirala S. Cardiac and electrocardiographical manifestations of acute organophosphate poisoning. Singapore Med J. 2004;45:385-389. 